\title{
Surgical management of avascular necrosis of the femoral head: an update
}

This article was published in the following Dove Press journal:

Orthopedic Research and Reviews

6 November 2012

Number of times this article has been viewed

\section{Omer Karatoprak \\ Sinan Karaca}

Orthopaedics and Traumatology Department, Kadikoy Florence Hospital, Kadikoy, Istanbul, Turkey
Correspondence: Omer Karatoprak Orthopaedics and Traumatology Department, Kadikoy Florence Hospital, 63 Bagdat Cd, Kiziltoprak, Kadikoy, Istanbul, Turkey

Tel +90 2l 64500303

Email karatoprako@yahoo.com

\begin{abstract}
Osteonecrosis or avascular necrosis of the femoral head (ANFH) is a progressive, multifactorial, and disabling disease that can result in significant clinical morbidity and affect patients of any age, including young and active patients. The pathogenesis and etiology of nontraumatic ANFH has not been elucidated completely, but could be mainly due to an inadequate blood supply, causing death of osteocytes and bone marrow cells. Surgical procedures like core decompression, nonvascularized autologous bone grafts, porous tantalum implant procedures, and various osteotomies have been used to delay progression of the disease and conversion to total hip arthroplasty. Noninvasive treatment modalities like pharmacologic measures, electrical stimulation, shock wave therapy, and electromagnetic field therapy are also used to treat ANFH. Various efforts have been made in an attempt to enhance the healing of osseous defects at the femoral head before collapse occurs. Current treatment techniques for ANFH have varying results, according to the patient population and disease stage involved. With modifications of older techniques and developing technologies, treatment strategies have the ability to alter the course of ANFH. Further management options are required for the treatment of ANFH, and will be widely studied in the coming decades.
\end{abstract}

Keywords: avascular necrosis, osteonecrosis, femoral head, total hip arthroplasty, core decompression, hip

\section{Introduction}

Osteonecrosis or avascular necrosis of the femoral head (ANFH) is a progressive, multifactorial, and disabling disease that can result in significant clinical morbidity and may affect patients of any age, including young and active patients. The pathogenesis and etiology of nontraumatic ANFH has not been elucidated completely, but could be mainly due to an inadequate blood supply causing death of osteocytes and bone marrow cells. ${ }^{1}$

Total hip arthroplasty is the most common definitive way of treating high-grade ANFH. This disorder is commonly seen in young adults, so joint-sparing therapeutic techniques have been the focus of research in the last decade. Clearly, ANFH is a challenging disorder to treat, but developments in basic science and clinical investigation will enable effective treatment options in the future.

\section{Factors affecting treatment outcome Radiological findings}

The primary radiological findings which determine the treatment outcome are impairment of the femoral head and whether femoral head collapse and acetabular involvement 
has occurred or not. ${ }^{1-3}$ The "crescent sign" observed before occurrence of femoral head collapse may indicate future mechanical failure. When hip joint surface involvement is less than $15 \%$, this is considered to be a good prognostic factor and involvement above $30 \%$ is considered to be a bad prognostic factor. ${ }^{1,2}$

Femoral head collapse may have two bad prognostic features, the first one of which is collapse of the femoral joint surface of more than $2 \mathrm{~mm}$ and the second is the presence of a collapse field wider than $30 \%$ of the total femoral joint surface. ${ }^{1,3}$

In surgical treatment of ANFH, when deciding whether the femoral head will be preserved or not, acetabular involvement should be taken to account. Joint space preservation may also be found in cases with acetabular involvement. Sparing of the femoral head may result in treatment failure in such cases. ${ }^{1,2,4}$

\section{Intraoperative factors}

In addition to preoperative investigations, intraoperative findings are also important in deciding on the correct treatment option. Intraoperative arthroscopic investigation of the hip joint is suggested to determine the condition of the joint cartilage. ${ }^{1}$ When arthroscopy is not available, computed tomography scanning could be helpful. ${ }^{1}$

\section{Patient-specific factors}

Patient age, activity level, general health, and life expectancy are factors affecting selection of the best treatment method and its success. Range of movement in the hip joint, presence of pain, and limping should also be taken into account. Major surgical interventions should be avoided in patients with systemic disease and a short life expectancy. Therefore, similar lesions may be treated in different ways in different patients. Definitive surgical intervention, eg, total hip arthroplasty, is preferred in patients whose general health could not withstand a second procedure. Duration of preoperative symptoms is another factor that determines the success of treatment. ${ }^{1}$

\section{Nonoperative treatment}

A meta-analysis in 1996 investigated the results of conventional treatment for ANFH, and observed that in 819 patients followed for 34 months without weight-bearing, more than $80 \%$ had a negative outcome. Consequently, the authors stated that the conventional approach has no place in the treatment of ANFH. ${ }^{1}$ Currently, conventional pharmacological and physical treatment methods continue to be used despite these negative findings. The main pharmacological agents used for treatment of ANFH are antilipidemic agents, anticoagulants, vasodilators, bisphosphonates, anabolic steroids, and prostacyclin derivatives. ${ }^{1-4}$ Electromagnetic stimulation, ${ }^{5}$ extracorporeal shock wave therapy, ${ }^{6}$ and hyperbaric oxygen ${ }^{1}$ are the main physical methods used in the conventional treatment of ANFH.

\section{Operative treatment}

Conventional surgery for ANFH is divided into two groups, ie, femoral head-sparing and arthroplasty procedures. The femoral head-sparing technique is likely to have a good result if performed before femoral head collapse occurs. On the other hand, arthroplasty is preferred in cases where collapse has occurred.

\section{Femoral head-sparing techniques}

Core decompression, combined core decompression (with vascularized bone grafting and nonvascularized bone grafting), and rotational osteotomies are femoral headsparing methods. ${ }^{4}$

\section{Core decompression}

In 2000, Castro and Barrack analyzed the results of 22 studies involving application of core decompression, including eight studies involving nonoperative treatment. They concluded that the outcome of core decompression performed in the early stages is significantly better than that of conservative therapy $^{1}$ (Figure 1).

The efficacy of core decompression and its limited indications are controversial topics in the literature. ${ }^{7,8}$ The choice of technique depends on the number of tunnels drilled and the diameter of the tunnels. Mont et al reported a patient series followed up for 2 years, and $71 \%$ of 45 stage I hip cases treated with a $3.2 \mathrm{~mm}$ multiple hole procedure had positive results. ${ }^{1}$

In addition to core decompression, electrical stimulation, growth factors, bone morphogenic protein, autologous bone marrow cell concentrate, and tantalum rod implantation have been used to increase efficacy. Vascularized or nonvascularized bone grafts have also been used in combination with core decompression. Electrical stimulation has been reported to have a positive impact in patients who were treated with core decompression. ${ }^{8,9}$ Mont et al reported positive outcomes in $18(86 \%)$ of 21 hips with allografts impregnated with bone morphogenic protein. ${ }^{10}$ In 2004, Liebermann et al used an autogenous fibular graft with $50 \mathrm{mg}$ of bone morphogenic protein in his surgical series of 17 hip cases (15 stage IIA, 

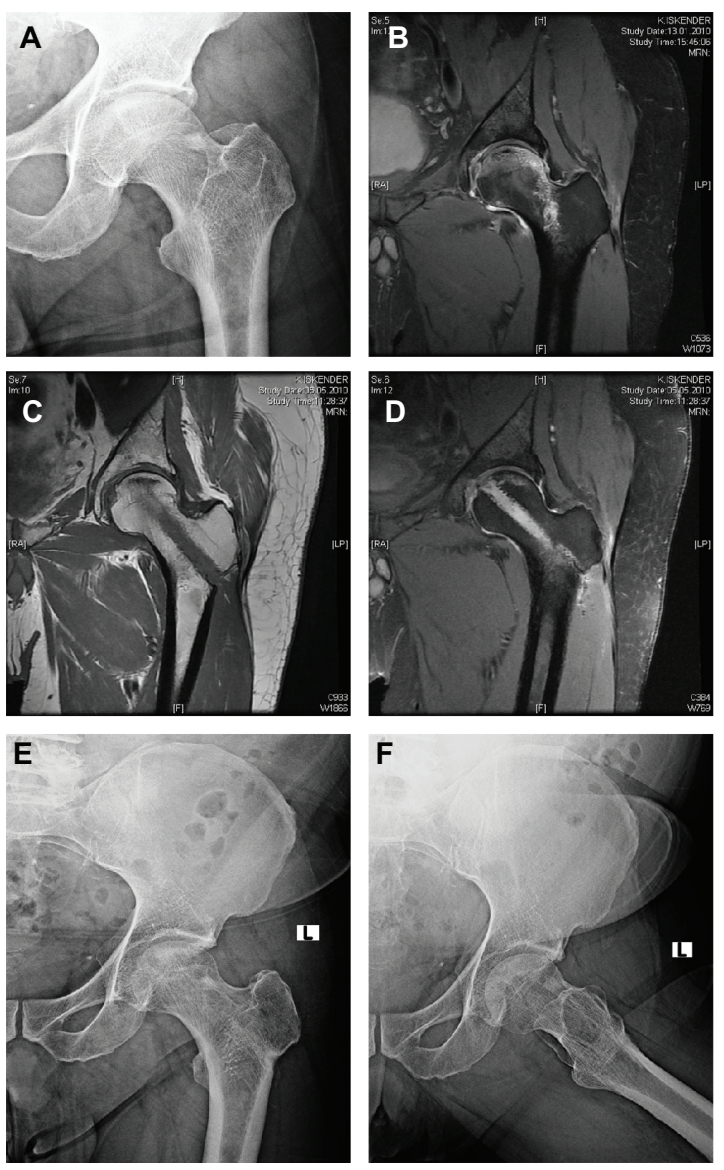

Figure I Plain radiographs and MRI scans of the hip of a 62-year-old man with osteonecrosis of the left femoral head. (A) Anteroposterior radiographs of the hip showing there is no collapse of the femoral head. (B) Preoperative MRI of the femoral head confirms the presence of an osteonecrotic lesion. The patient had core decompression.(C and D) Postoperative 4 months MRI. (E and F) One year later anteroposterior and lateral radiographs showed no collapse of the femoral head. Abbreviation: MRI, magnetic resonance imaging.

1 stage IIB, 1 stage III). They reported that $93 \%$ of hips with stage IIA disease had positive results, and that three with stage IIA, IIB, or III disease required total hip replacement. ${ }^{11}$ In another study, the tunnel was filled with either an autogenous iliac bone graft, an autogenous iliac bone graft \pm demineralized bone matrix, or an allogenic bone graft after core decompression. Overall, positive results were reported for $65 \%$ of cases. ${ }^{12,13}$

Autologous concentrated bone marrow-derived mononuclear cell concentrate was first used in the treatment of osteonecrosis in the 1990s, and has been reported to have positive results. Effectiveness of bone marrow cell transfer depends on the osteogenic effect of the transplanted mononuclear cells on the femoral head. This effect is the result of angiogenic cytokines being secreted by stromal bone marrow cells injected into the femoral head and the ensuing angiogenesis. ${ }^{14}$ Hernigou and Beaujean have published on the results of core decompression and bone marrow cell injection in 189 cases. Only nine of 145 patients with stage I or II disease needed total hip replacement. ${ }^{15}$ Gangji et al used core decompression and bone marrow cell injection in 13 patients with stage I or II osteonecrosis of the femoral head, all of whom remained pain-free and did not require total hip replacement during an average follow-up period of 2 years. ${ }^{16}$ In their study in 2011, Gangji et al divided 24 early-stage hip cases into two groups and used either core decompression or core decompression \pm bone marrow cell injection. These patients were followed up for 5 years. While eight of 11 hips in the control group progressed to the fracture stage, only three of 13 showed progression in the bone marrow group. ${ }^{17}$ Karatoprak et al used CD34+ cell concentrate, known to be both vasculogenic and osteogenic, in nine stage I or II hip cases following core decompression, and over a follow-up period of 27 months, there was no progression and no need for further surgical intervention in any of the cases. ${ }^{18}$

Following core decompression, mesenchymal stem cells cultured on a tantalum rod were used to prevent collapse of the joint surface. ${ }^{19}$ In a study conducted in 2010 in China, porous tantalum rod was suggested for use in the early and intermediate stages. ${ }^{20}$ Floerkemeier et al compared the results of conventional core decompression and tantalum rods, and reported better results using multiple holes created with $10 \mathrm{~mm}$ wide drills. ${ }^{21}$

\section{Nonvascularized bone grafting}

Nonvascularized bone grafting can be used to support subchondral bone and joint cartilage by removing necrotic bone tissue and replacing it with a cortical or cancellous bone graft. Three different nonvascularized grafting techniques have become popular over time. Using the Phemister technique, grafting is performed through a core decompression tract. The second method involves grafting performed through a window or a trapdoor in the femoral head. The third method is grafting through a window created at the femoral neck or femoral head-neck junction. ${ }^{22}$

In the literature, core decompression and nonvascularized grafting were used in 20 stage I or II hip cases. Tibial autografting, fibular autografting, and fibular allografting were used, respectively, in three, seven, and 10 hips. Cases were followed up for a minimum of 2 years, and positive results were obtained in 17 patients. In 17 hips, the graft was placed within the lesion and adjacent to the subchondral bone. In the remaining three hips, grafts were inserted into the lesion to the level of the transitional zone between the infarct and normal bone. After performing core decompression in 85 hips with ANFH in a study in 2005, Keizer et al used 
cortical tibial autografts and fibular allografts, respectively, in 18 and 62 patients, respectively. In their surgical series of 47 stage II cases, they reported $44 \%$ revisions and 54\% negative results after an average follow-up period of 4 years, and after 6 years, survival rates were $75 \%$ and $49 \%$ in patients with tibial autografting and fibular allografting, respectively. The authors concluded that grafting position had no effect on the outcome of surgery; however, cortical tibial autografting provided better results due to the osteogenic effect. ${ }^{24}$ In 2008 , a group of investigators reported that the use of cancellous chips supported with bone morphogenetic protein-7 during nonvascularized grafting via a trapdoor technique avoided the need for secondary surgical intervention in $80 \%$ of stage II and III hip cases. ${ }^{22,24}$

\section{Vascularized bone grafting}

Following the removal of necrotic bone tissue from the femoral head, the contralateral fibula with its nutrient vessels is introduced through the head and neck of the femur, and the vessels are anastomosed microsurgically to the anterior circumflex artery and vein. ${ }^{25}$ Judet and Gilbert reported in 2001 that fibular grafting in stage II and III patients under 40 years of age yielded positive results in $80 \%$ of cases over a follow-up period of 18 years. However, they underlined that vascularized fibular grafting is not a good option in advanced cases. ${ }^{26}$ In another study, vascularized fibular grafting was used in stage II and III cases with an average follow-up of 13.9 years, with negative results and reverse total hip arthroplasty needed in $10.5 \%$ of cases. ${ }^{25}$ Tetik et al compared the results of vascularized and nonvascularized fibular grafting and found no significant radiological difference in outcome between the two procedures. However, the vascularized group had clinically superior results. ${ }^{27}$ Positive results have also been reported using vascularized pedicle iliac bone grafting combined with transtrochanteric anterior rotational osteotomy in young adults with advanced ANFH. ${ }^{28-31}$

In 2010, Zhao et al reported the results of en bloc vascularized trochanteric grafting in 195 hip cases. The technique involved translocation of a $3 \mathrm{~cm}$ long and $2 \mathrm{~cm}$ wide graft from the anterolateral trochanter along with the transverse branch of the lateral femoral circumflex artery to the necrotic region harvested from the femoral head-neck junction in stage II-IV cases. Postoperative digital subtraction angiography performed in 46 patients showed perfusion in the graft and the femoral head in 42 cases. After an average follow-up of 8 years, total hip arthroplasty was not required in 172 patients, whereas 23 patients needed conversion to total hip arthroplasty ${ }^{32}$ (Figure 2).

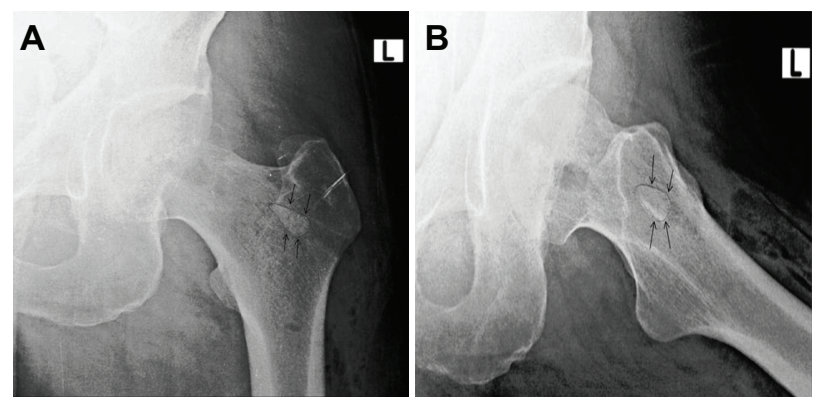

Figure 2 Anteroposterior (A) and lateral radiographs (B) of the left hip of a 57 -year-old man taken 16 months after application of core decompression and bone marrow cell injection.

\section{Osteotomy}

Transtrochanteric rotational osteotomy was developed by Sugioka and Yamamoto in 1978. This procedure involves transposing an intact area to a weight-bearing portion of the joint, thus resulting in transfer of a necrotic area to a non-weight-bearing portion. The clinical and radiographic prognoses after a transtrochanteric rotational osteotomy depend mainly on the ratio of the transposed intact area to the acetabular weight-bearing portion after osteotomy. The intact area transposed should be more than $36 \%$ of the weight-bearing region. ${ }^{33,34}$

In their surgical series of 70 patients, Yamamoto et al used anterior rotational osteotomy in 57 hips with ANFH and performed rotational osteotomy in 13 hips. At the end of a 10-year follow-up period, necrotic fields had healed with osteosclerosis in $71 \%$ of cases, and the remaining cases healed with normal bone tissue. None showed progression. ${ }^{33}$

In their paper published in 2008, Sugioka and Yamamoto stated that they perform posterior transtrochanteric osteotomy when the necrotic region is located in the mid and posterior sections of the femoral head. In their study following 46 stage II and III hips for a mean of 12 years, they reported a mean 52-point improvement in Harris hip score. Progression was not radiologically observed in $65 \%$ of cases, while osteoarthritic changes were found in $28 \%$, but total hip arthroplasty was not required. ${ }^{34}$

Intertrochanteric varus wedge osteotomy, commonly used in osteoarthritis, was adapted for ANFH and used in 47 patients by Ito et al, who reported positive results for Harris hip score in $74 \%$ of cases and joint space narrowing and osteoarthritic changes in $26 \%$ of cases during an average follow-up period of 18.1 years. Only six of their patients required total hip replacement or hemiarthroplasty. The average shortening was $19 \mathrm{~mm}$, and the authors concluded that shortening is a problem, so curved varus osteotomy may be preferred. ${ }^{35}$ On the other hand, Zhao et al reported a 
success rate of $83.5 \%$, after a mean 12.3 years of follow-up in their case series of curved varus osteotomy. ${ }^{36}$ Good outcomes were also reported in a study where transtrochanteric rotational osteotomy and varization were used concurrently in wide lesions. ${ }^{37}$

\section{Arthroplasty}

In patients with a large necrotic area, joint preservation is not indicated and prosthetic replacement is preferred. ${ }^{38}$ Hemiresurfacing, total hip resurfacing, and conventional total hip arthroplasty are contemporary arthroplasty solutions in cases of ANFH where the femoral head cannot be spared. ${ }^{39}$ Hemiresurfacing arthroplasty replaces only the side of the femoral head, whereas total resurfacing arthroplasty replaces the acetabular side as well. ${ }^{38}$ Hemiresurfacing has been referred to as "time-buying" surgery for patients with Ficat stage II and III disease. Recently, total hip resurfacing has become an alternative for both total hip arthroplasty and hemisurfacing. ${ }^{39}$

Jameson et $\mathrm{al}^{40}$ performed resurfacing via articular surface replacement in 214 patients with ANFH who were followed up for an average of 43 months; during this time, 5.6\% of patients had revision surgery and $1.9 \%$ had early femoral neck fracture. From these negative cases, they concluded that use of resurfacing in young and active patients, performing conventional total hip replacement in the rest of the patients, and use of implants with a wide-sized component option improved the success of treatment. A study reported in 2011 compared the results of hemiresurfacing and total resurfacing arthroplasty. Using need for revision surgery and pain evaluation as the criteria, total resurfacing arthroplasty was found to be superior. ${ }^{38}$

In 2009, McGrath et al reported their results with primary total hip arthroplasty versus surface replacement revised with total hip arthroplasty. Their study included two groups of 39 hips each, and it was concluded that following total or hemisurface replacement, the results of revision total hip arthroplasty were equivalent to those with primary total hip arthroplasty, so surface replacement is preferable for buying time in patients with ANFH. ${ }^{41}$

\section{Recommendations for treatment}

Core decompression should be performed either with follow-up or vascularized/nonvascularized bone grafting in asymptomatic patients with stage I or II disease. In stages IC, IIC, III, and IVA, grafting should be accompanied by core decompression, osteotomy, and arthroplasty in major lesions. Either resurfacing or total hip arthroplasty could be used in cases of Stage IVB, IVC, V, and VI disease, according to the extent of femoral head involvement. ${ }^{2,7}$

\section{Conclusion}

ANFH is a progressive, multifactorial, and disabling disease commonly seen in younger adults. After collapse of the femoral head and early osteoarthritis of the hip joint, arthroplasty could be a suitable treatment option if nonoperative and joint-sparing procedures fail. Basic science research that can be used in clinical management has progressed rapidly, and these advances offer great promise for the future treatment of osteonecrosis of the hip. Clearly, ANFH is a challenging disorder to treat, but with ongoing developments in basic science and clinical investigation, more effective treatment options should become available in the future.

\section{Disclosure}

The authors report no conflicts of interest in this work.

\section{References}

1. Mont MA, Jones LC, Hungerford DS. Nontraumatic osteonecrosis of the femoral head: ten years later. J Bone Joint Surg Am. 2006;88: 1117-1132.

2. Liberman JR. Osteonecrosis of the hip and knee. In: Barrack. RL, editor. Orthopaedic Knowledge Update: Hip and Knee Reconstruction. Rosemont, IL: American Academy of Orthopedic Surgeons; 2011.

3. Mont MA, Hungerford DS. Non-traumatic avascular necrosis of the femoral head. J Bone Joint Surg Am. 1995;77:459-474.

4. Petrigliano FA, Liberman JR. Osteonecrosis of the femoral head. In: Adult Reconstruction. Hip Part B - Evaluation and Treatment of Hip Disorders. 1st ed. 2007.

5. Ishida M, Fujioka M, Takahashi KA, Arai Y, Kubo T. Electromagnetic fields: a novel prophylaxis for steroid-induced osteonecrosis. Clin Orthop Relat Res. 2008;466:1068-1073.

6. Zelle BA, Gollwitzer H, Zlowodzki M, Bühren V. Extracorporeal shock wave therapy: current evidence. J Orthop Trauma. 2010;24 Suppl 1: S66-S70.

7. Lieberman JR, Engstrom SM, Meneghini RM, SooHoo NF. Which factors influence preservation of the osteonecrotic femoral head? Clin Orthop Relat Res. 2012;470:525-534.

8. Marker DR, Seyler TM, Ulrich SD, Srivastava S, Mont MA. Do modern techniques improve core decompression outcomes for hip osteonecrosis? Clin Orthop Relat Res. 2008;466:1093-1103.

9. Steinberg ME, Brighton CT, Corces A, et al. Osteonecrosis of the femoral head. Results of core decompression and grafting with and without electrical stimulation. Clin Orthop Relat Res. 1989;249:199-208.

10. Mont MA, Etienne G, Ragland PS. Outcome of nonvascularized bone grafting for osteonecrosis of the femoral head. Clin Orthop Relat Res. 2003;417:84-92.

11. Lieberman J, Conduah A, Urist MR. Treatment of osteonecrosis of the femoral head with core decompression and human bone morphogenetic protein. Clin Orthop Relat Res. 2004;429:139-142.

12. Wang B1, Sun W, Shi ZC, et al. Treatment of nontraumatic osteonecrosis of the femoral head using bone impaction grafting through a femoral neck window. Int Orthop. 2010;34:635-639.

13. Bednarek A, Atras A, Gagała J, Kozak Ł. Operative technique and results of core decompression and filling with bone grafts in the treatment of osteonecrosis of femoral head. Ortop Traumatol Rehabil. 2010;12:511-518. 
14. Wang BL, Sun W, Shi ZC, et al. Treatment of nontraumatic osteonecrosis of the femoral head with the implantation of core decompression and concentrated autologous bone marrow containing mononuclear cells. Arch Orthop Trauma Surg. 2010;130:859-865.

15. Hernigou P, Beaujean F. Treatment of osteonecrosis with autologous bone marrow grafting. Clin Orthop Relat Res. 2002;405:14-23.

16. Gangji V, Hauzeur JP, Matos C, De Maertelaer V, Toungouz M, Lambermont M. Treatment of osteonecrosis of the femoral head with implantation of autologous bone-marrow cells. A pilot study. J Bone Joint Surg Am. 2004;86A:1153-1160.

17. Gangji V, De Maertelaer V, Hauzeur JP. Autologous bone marrow cell implantation in the treatment of non-traumatic osteonecrosis of the femoral head: five year follow-up of a prospective controlled study. Bone. 2011;49:1005-1009.

18. Karatoprak O, Korkmaz MF, Kara AN, Gogus A, Isiklar ZU. Early results of autologous mononuclear bone marrow cell implantation in nontraumatic avascular necrosis of the femoral head. Acta Orthop Traumatol Turc. 2008;42:178-183.

19. Xu M, Peng D. Mesenchymal stem cells cultured on tantalum used in early-stage avascular necrosis of the femoral head. Med Hypotheses. 2011;76:199-200.

20. Liu G, Wang J, Yang S, Xu W, Ye S, Xia T. Effect of a porous tantalum rod on early and intermediate stages of necrosis of the femoral head. Biomed Mater. 2010;5:065003.

21. Floerkemeier T, Lutz A, Nackenhorst U, et al. Core decompression and osteonecrosis intervention rod in osteonecrosis of the femoral head: clinical outcome and finite element analysis. Int Orthop. 2011;35: 1461-1466.

22. Thorsten M, Seyler TM, Marker DR, Ulrich SD, Fatscher T, Mont MA. Nonvascularized bone grafting defers joint arthroplasty in hip osteonecrosis. Clin Orthop Relat Res. 2008;466:1125-1132.

23. Buckley PD, Gearen PF, Petty RW. Structural bone-grafting for early atraumatic avascular necrosis of the femoral head. J Bone Joint Surg Am. 1991;73:1357-1364.

24. Keizer SB, Kock NB, Dijkstra PD, Taminiau AH, Nelissen RG. Treatment of avascular necrosis of the hip by a non-vascularised cortical graft. J Bone Joint Surg Br. 2006;88:460-466.

25. Yoo MC, Kim KI, Hahn CS, Parvizi J. Long-term follow-up of vascularized fibular grafting for femoral head necrosis. Clin Orthop Relat Res. 2008;466:1133-1140.

26. Judet H, Gilbert A. Long-term results of free vascularized fibular grafting for femoral head necrosis. Clin Orthop Relat Res. 2001;386: 114-119.

27. Tetik C, Başar H, Bezer M, Erol B, Ağir I, Esemenli T. Comparison of early results of vascularized and non-vascularized fibular grafting in the treatment of osteonecrosis of the femoral head. Acta Orthop Traumatol Turc. 2011;45:326-334.
28. Nakamura Y, Kumazawa Y, Mitsui H, Toh S, Katano H. Combined rotational osteotomy and vascularized iliac bone graft for advanced osteonecrosis of the femoral head. J Reconstr Microsurg. 2005;21: 101-105.

29. Matsusaki H, Noguchi M, Kawakami T, Tani T. Use of vascularized pedicle iliac bone graft combined with transtrochanteric rotational osteotomy in the treatment of avascular necrosis of the femoral head. Arch Orthop Trauma Surg. 2005;125:95-101.

30. Fuchs B, Knothe U, Hertel R, Ganz R. Femoral osteotomy and iliac graft vascularization for femoral head osteonecrosis. Clin Orthop Relat Res. 2003;412:84-93.

31. Eisenschenk A, Lautenbach M, Schwetlick G, Weber U. Treatment of femoral head necrosis with vascularized iliac crest transplants. Clin Orthop Relat Res. 2001;386:100-105.

32. Zhao D, Wang B, Guo L, Yang L, Tian F. Will a vascularized greater trochanter graft preserve the necrotic femoral head? Clin Orthop Relat Res. 2010;468:1316-1324.

33. Yamamoto T, Ikemura S, Iwamoto Y, Sugioka Y. The repair process of osteonecrosis after a transtrochanteric rotational osteotomy. Clin Orthop Relat Res. 2010;468:3186-3191.

34. Sugioka Y, Yamamoto T. Transtrochanteric posterior rotational osteotomy for osteonecrosis. Clin Orthop Relat Res. 2008;466:1104-1109.

35. Ito $\mathrm{H}$, Tanino $\mathrm{H}$, Yamanaka $\mathrm{Y}$, et al. Long-term results of conventional varus half-wedge proximal femoral osteotomy for the treatment of osteonecrosis of the femoral head. J Bone Joint Surg Br. 2012;94: 308-314.

36. Zhao G, Yamamoto T, Ikemura S, et al. Radiological outcome analysis of transtrochanteric curved varus osteotomy for osteonecrosis of the femoral head at a mean follow-up of 12.4 years. J Bone Joint Surg Br. 2010;92:781-786.

37. Biswal S, Hazra S, Yun HH, Hur CY, Shon WY. Transtrochanteric rotational osteotomy for nontraumatic osteonecrosis of the femoral head in young adults. Clin Orthop Relat Res. 2009;467:1529-1537.

38. Kabata T, Maeda T, Tanaka K, et al. Hemi-resurfacing versus total resurfacing for osteonecrosis of the femoral head. J Orthop Surg (Hong Kong). 2011;19:177-180.

39. Amstutz HC, Le Duff MJ. Hip resurfacing results for osteonecrosis are as good as for other etiologies at 2 to 12 years. Clin Orthop Relat Res. 2010;468:375-381.

40. Jameson SS, Langton DJ, Nargol AV. Articular surface replacement of the hip: a prospective single-surgeon series. J Bone Joint Surg Br. 2010;92:28-37.

41. McGrath MS, Marker DR, Seyler TM, Ulrich SD, Mont MA. Surface replacement is comparable to primary total hip arthroplasty. Clin Orthop Relat Res. 2009;467:94-100.
Orthopedic Research and Reviews

\section{Publish your work in this journal}

Orthopedic Research and Reviews is an international, peer-reviewed, open access journal focusing on the patho-physiology of the musculoskeletal system, trauma, surgery and other corrective interventions to restore mobility and function. Advances in new technologies, materials, techniques and pharmacological agents are particularly welcome. The journal welcomes

\section{Dovepress}

original research, clinical studies, reviews \& evaluations, expert opinion and commentary, case reports and extended reports. The manuscript management system is completely online and includes a very quick and fair peer-review system, which is all easy to use. Visit http://www.dovepress. com/testimonials.php to read real quotes from published authors. 